\title{
En memoria: Dr. Lázaro Benavides Vázquez
}

\author{
In memory: Dr. Lázaro \\ Benavides Vázquez.
}

"Don Lázaro, nuestro amigo, al que cariñosamente al cumplir 100 años, la familia le regaló un arbolito bonsái "SEQUOIA", como un homenaje a su grandeza, resistencia y longevidad.

A sus 102 años de vida, unos días después de cumplirlos, al hacerle referencia a la grandeza de cumplir y vivir 102, nos corrigió y nos dijo:

"No, 102 ya no, está corriendo el 103".

"Un orgullo ser su amigo"

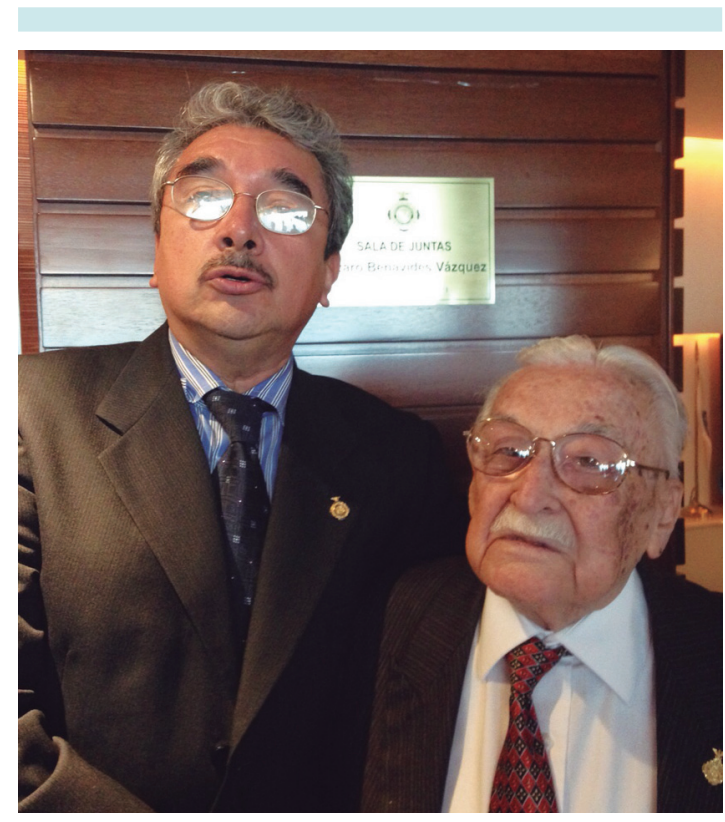

www.actapediatrica.org.mx
Nace el 6 de marzo de 1914 en la Ciudad de Piedras Negras, Coahuila. Estudió High School en Eagle Pass, Texas, donde obtiene su grado. En 1930, obtiene el primer lugar para el Estado de Texas en el certamen anual del Foro Nacional de Estudiantes Americanos, correspondiendo esto, al $6^{\circ}$ lugar en toda la Unión Americana.

A principio de los años 30's, llega a la Ciudad de México a estudiar el bachillerato en el Antiguo Colegio de San Ildefonso por dos años, en donde la relación con médicos amigos de la familia le da la iniciativa de estudiar medicina enrolándose en la Escuela Médico Militar en la Generación 1935-1940; en ésta, conoce algunos maestros inolvidables como Fernando Ocaranza quien también fue rector de la UNAM; Gustavo Baz Prada, Director de la Facultad Nacional de Medicina, de la Escuela Médico Militar y el vigésimo tercer Rector de la UNAM y a Jesús Lozoya Solís, entre otros. Recibe la cátedra y la inspiración de Don Federico Gómez, quedando prendado de la pediatría y esto lo marca para toda la vida.

En 1941 se gradúa con el grado de Mayor, ejerciendo tareas encomendadas por algunos años. Se da de baja como médico militar con grado de teniente coronel en 1956. En este trayecto, estudia enfermedades infecciosas en el Municipal Contagious Disease Hospital y posteriormente en el Children's Memorial Hospital, en la Ciudad de Chicago, y en la Universidad de Tulane, Nueva 
Orleans, donde cursa una maestría en salud pública y en administración médica, obteniendo la "Medalla Delta-Omega", otorgada al mejor estudiante de su generación. Estos estudios lo proyectan como un formador de instituciones asistenciales nacionales de primer orden, donde se da asistencia, enseñanza e investigación hasta los tiempos que vivimos.

Al regreso de los Estados Unidos, se incorpora al Hospital Infantil de México en el que forma parte de la primera generación de internos (médicos residentes) desde 1943. A partir de esa fecha, inicia una meritoria carrera escalafonaria que incluye las posiciones de subresidente, residente, jefe de residentes, Titular del Servicio de Infectología y de la Oficina de Ediciones Médicas. En 1953, por invitación de Federico Gómez, se integra como subdirector del hospital, permaneciendo en este honroso cargo hasta el año de 1970.

En aquella época, tenía una consulta extraordinaria. Muy rica, y tenía muchísima clientela. Una vez le dijo don Federico Gómez: "Quiero que se venga de subdirector del Hospital Infantil de México, pero si usted lo acepta, piénselo un tiempo, porque tendrá que dejar la consulta. Usted decide, si es subdirector de tiempo completo o se retira a su clientela." Dijo entonces el Dr. Benavides: "Pues me gustó más la situación de funcionario que de pediatra de consultorio. Y me dediqué a la subdirección".

La labor de don Lázaro en esa inolvidable etapa del Hospital fue muy productiva; entre otras, se destaca su labor al frente del Boletín del Hospital Infantil de México, en el cual se plasma todo el acervo médico de investigación y la difusión de la institución a toda Latinoamérica. Asimismo, la creación de las áreas de Medicina Preventiva y de Rehabilitación Integral, que elevaron la labor asistencial del hospital a niveles insospechados. En esa época, se reconoce una de las etapas de oro del Hospital Infantil de México, cuando se dan excepcionales acciones en el campo asistencial, docencia e investigación, y luego en la formación de subespecialistas graduados en el extranjero, que regresaban y se hacían notables eminencias médicas, que crearon importantes especialidades pediátricas, constituyéndose en uno de los mejores hospitales pediátricos de América Latina.

En 1968 preside, organiza y coordina el primer Congreso Internacional de Pediatría con sede en la Ciudad de México, con la asistencia de 7,000 personas, evento que le da proyección internacional a la pediatría mexicana.

En 1968, por instrucciones del presidente de la República: Licenciado Gustavo Díaz Ordaz, y acciones directas de su esposa, la Sra. Guadalupe Borja de Díaz Ordaz (convencida de que era necesario construir un nuevo Hospital de niños en la capital de la Nación) se instruye al Arquitecto Pedro Ramírez Vázquez para que encabece este propósito. Una tarde de mayo, Lázaro Benavides une un diseño y programa ya realizado para la construcción de un hospital, así como su tiempo, talento, conocimiento, experiencia y liderazgo para rodearse de destacados pediatras mexicanos y logra darle a este plan arquitectónico, el diseño, estructura, organización e imaginación, así como lo más avanzado en la ciencia y tecnología, (inspirado en su visita a los mejores hospitales pediátricos del mundo), en conjunto con los mejores médicos especialistas y subespecialistas de la pediatría para construir e inaugurar el mejor y más moderno hospital de asistencia a la niñez de la época, el que es hoy Instituto Nacional de Pediatría, fundado el 6 de noviembre de 1970, bajo el nombre de Hospital Infantil de la Institución Mexicana de Asistencia a la Niñez (IMAN), estipulada en su decreto de origen el 19 de agosto de 1968 en el Diario Oficial de la Federación. Se convocó a importantes personalidades: Jesús Kumate, Joaquín Cravioto, 
Rafael Ramos Galván, Jesús Álvarez de los Cobos, Luis Sierra Rojas, entre otros.

El primero de julio de 1970, don Lázaro Benavides asume la Dirección General del entonces llamado Hospital del Niño del IMAN como director fundador, según consta en archivos y en el diploma en noviembre de 1980 signado por la Señora Carmen Romano de López Portillo, presidenta del Sistema Nacional para el Desarrollo Integral de la Familia. Fue también presidente de la Sociedad Mexicana de Pediatría de 1959 a 1961.

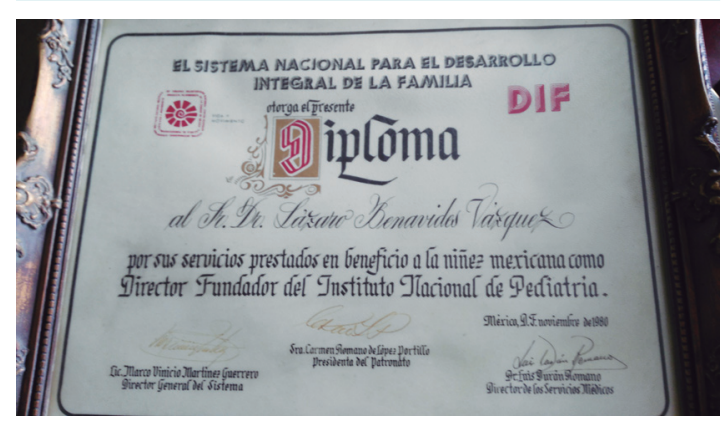

En 1980 fue fundador y en 1983, presidente del Consejo Mexicano de Certificación en Pediatría. En 1994, a los 80 años de edad, cursa un Diplomado en Bioética por la Universidad Anáhuac.

El 23 de octubre del 2000, día del médico, en el salón Adolfo López Mateos de la residencia oficial de Los Pinos, recibió del presidente de la República, Dr. Ernesto Zedillo Ponce de León, El premio a la "Excelencia Médica", un diploma con la acreditación y la medalla conmemorativa por sus contribuciones fundamentales al desarrollo de la pediatría en México y fue considerado como el "MEJOR MÉDICO PEDIATRA DEL SIGLO XX". Esta distinción, única en su género, hizo que instituciones del campo de la medicina como la Dirección General de Sanidad, la Secretaría de la Defensa Nacional, la Secretaría de Salud, la Universidad Nacional Autónoma de México, la Sociedad Mexicana de Pediatría y la pediatría en el país, fueron copartícipes del reconocimiento, un galardón logrado por sus largos años de esfuerzo y esmerada dedicación al estudio y al ejercicio de su profesión a la que se consagró por completo y verdadero amor a la niñez, sobre todo a la de escasos recursos económicos.

En 1997 recibió de la Academia Mexicana de Pediatría el premio al mérito académico "Dr. Mario A. Torroella"; un premio que se otorga al médico pediatra que se haya distinguido por sus tareas en beneficio de la niñez, de la pediatría y de la academia.

La Academia Mexicana de Pediatría también ha instituido un premio anual que lleva su nombre a la mejor investigación pediátrica, entregado en los congresos anuales de la Asociación Mexicana de Pediatría.

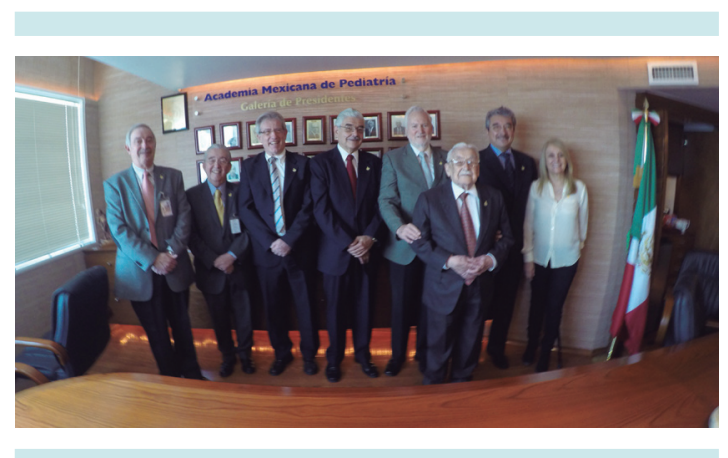

El Dr. Benavides fue Director General de la Dirección de Servicios Médicos de la UNAM por 14 años, por lo que la biblioteca de esta instancia lleva su nombre, al igual que una importante calle de Saltillo Coahuila.

En el año 2000, el Ayuntamiento de Piedras Negras lo distinguió dentro de los festejos conmemorativos del 150 aniversario de su fundación, entregándole el trofeo "Piedras Negras", y se impuso su nombre a la avenida que antes se llamó Insurgentes. 
Recibió una distinción en reconocimiento a sus "generosas aportaciones a la Asociación Internacional de Pediatría (AIP), a nuestros niños del mundo y por ser un miembro distinguido de esta Asociación", en el Congreso Centenario de la Asociación Internacional de Pediatría, el 4 de agosto del 2010, con sede en Johannesburgo, Sudáfrica.

En 2010 la Sociedad Mexicana de Pediatría realiza en su honor, el Congreso Conmemorativo del 80 Aniversario y le otorga la "Medalla Lázaro Benavides Vázquez", distinguiendo también con ella a todos los expresidentes de la organización.

En 2011 recibe el Reconocimiento de la Confederación Nacional de Pediatría de México, por su labor y como decano de la pediatría mexicana.

En 2014 es nombrado Presidente Honorario Vitalicio de la Academia Mexicana De Pediatría, por la mesa directiva de la corporación.

Desde mayo de 2015 la Sala de Juntas de la Academia Mexicana de Pediatría, lleva el nombre "Dr. Lázaro Benavides Vázquez".

El Dr. Lázaro Benavides Vázquez fallece el 16 de abril de este año, a los 102 años de edad, en la Ciudad de México. Ha ido al reencuentro con su amada compañera y fortaleza de toda la vida, su esposa Ofelia. Deja una gran familia conformada por más de 70 personas, encabezadas por sus hijos Héctor, Ofelia y Emilia, una prima de más de 90 años, y hasta bisnietos pequeños, todos unidos y confortados alrededor de su gran ejemplo en vida, hoy convertido en herencia espiritual.

Descanse en paz el decano de la pediatría mexicana, esposo y padre de familia ejemplar, incansable, educado, muy culto, sensible, político y estratega honorable y honrado, recio de carácter, pero respetuoso, con un gran sentido del humor, maestro y ejemplo a seguir de miles. Uno de los forjadores de la atención pediátrica institucional, intachable dirigente, líder, participe durante 17 años en la subdirección, organización, administración, desarrollo y proyección en todas las áreas de la pediatría en su momento del primer hospital infantil del país, el Hospital Infantil de México Dr. Federico Gómez Santos y coordinador, estratega, fundador y primer director del segundo hospital infantil en México, el Instituto Nacional de Pediatría, y que hoy son punta de lanza, como hospitales escuela e insignia, de la atención integral del niño en el DF y en México.

Don Lázaro Benavides es, además, uno de los forjadores de la pediatría organizada de México contemporáneo.

Descanse en paz el decano de la pediatría Mexicana.

M en C. Julio César Ballesteros del Olmo Expresidente Academia Mexicana de Pediatría 